\title{
Using data to identify and reach the most vulnerable young people
}

\section{Adam Weiner \\ Population Council}

Follow this and additional works at: https://knowledgecommons.popcouncil.org/departments_sbsr-pgy

Part of the Demography, Population, and Ecology Commons, Family, Life Course, and Society Commons, Gender and Sexuality Commons, and the International Public Health Commons How does access to this work benefit you? Let us know!

\section{Recommended Citation}

Weiner, Adam. 2011. "Using data to identify and reach the most vulnerable young people," Promoting Healthy, Safe, and Productive Transitions to Adulthood Brief no. 10. New York: Population Council. 


\title{
Using data to identify and reach the most vulnerable young people
}

\author{
Prepared by Adam Weiner
}

$\mathrm{S}$ ince the early 1990s, Population Council staff have dedicated a great deal of attention to research, policies, and programs for young people in developing countries, recognizing that the social, economic, and biological events of this stage of the life cycle set the stage for the nature and quality of their adult lives. The diversity of adolescents' lives between and within countries and the early ages at which many young people assume adult roles mean that general approaches to youth issues, or ones that do not address this diversity and the uniqueness of the adolescent experience, will not reach those with the greatest needs. Strategies and interventions are needed to ensure equity in access to services that are relevant to young people's unique needs, ultimately providing them with the opportunity for a healthy transition to adulthood.

To understand the experiences of adolescents, researchers and other stakeholders rely on a wide range of data. Information on population distribution and other general demographic factors provide a foundation for understanding young people within a certain context. Additional data on their education, household composition, and sexual and reproductive health are equally important for establishing an evidence base for use in the design of programs and policies.

In the absence of appropriately disaggregated data, misconceptions about adolescence and the circumstances surrounding young people in developing countries have dominated the discourse. The Council has responded to this issue by analyzing data and producing reports to illustrate the diversity of young people's lives for use in program planning and decisionmaking.

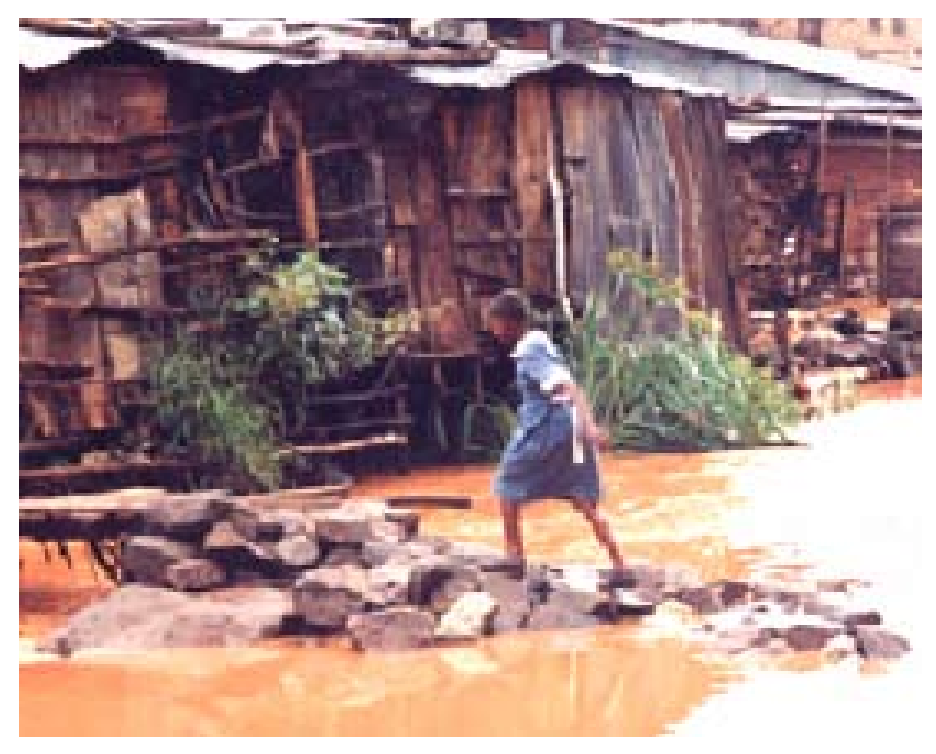

\section{DHS Adolescent Data Guides}

Through workshops and conferences with partners around the world, the Council seeks to promote a better understanding of the adolescent experience and advocates for the development of programs based on evidence. To facilitate such fact-based planning, the Council has been using valuable sources of data, such as the Demographic and Health Surveys (DHS), to generate evidence to support policy analysis and program design. The DHS country reports are a series of surveys conducted regularly throughout the developing world 
to advance the understanding of health and population trends (MeasureDHS 2011). Data on adolescents are gathered through direct interviews of those aged 15 and older. Information about those younger than 15 is obtained through the household roster. In 2001, the Council produced a series of reports using the DHS called Facts about Adolescents from the Demographic and Health Survey:

Statistical Tables for Program Planning. This series included reports for 47 countries and was the first large-scale effort from the Council to make available high-quality data about the lives of young people. Over time, an updated series using more recent DHS became essential. Understanding of the types of data necessary for targeted policy analysis and program development had increased. In 2009, the Council, with support from UNFPA, launched the series entitled The Adolescent Experience In-Depth: Using Data to Identify and Reach the Most Vulnerable Young People, commonly referred to as the DHS Adolescent Data Guides.

The DHS Adolescent Data Guide series has as its source the most recent DHS, with only a few exceptions, for 51 countries. For those countries with more than one DHS since 2000, multiple reports can be used to examine change over time (assuming that the questions and sample frame have not changed). The data in each report cover young people aged 10-24 and are presented in tables, charts, and maps in order to provide a wide range of accessible information in a user-friendly format.

In light of the need for data that highlight the diversity of young people's experiences in the countries where they live, the Data Guides offer an in-depth exploration of indicators that were carefully selected by Council researchers and their collaborators. Each report is divided into three sections and contains a topical narrative that focuses on the policy and programmatic implications of the different indicators. The three sections are:

1. Mapping the vast diversity among adolescents-An overview of adolescents aged 10-24, including differences in age, sex, living arrangements, schooling and marital status, and urban/ rural residence. The goal is to identify large and potentially vulnerable subgroups of adolescents in need of attention.

2. Key transitions among young adolescents that lead to disadvantage-A focus on the 10-14 age range, a time when adolescents start their transition into potentially vulnerable phases of life.

3. Context of sexual activity-An overview of the context of sexual relations, with data on child marriage and pregnancy rates, as well as data related to the gender norms that often frame the onset and terms of sexual and marital relationships. In addition, data on HIV knowledge and testing, contraceptive use, antenatal care, and delivery assistance are included wherever possible.

For all indicators, data are disaggregated by age, sex, region, and urban/rural residence. Other key indicators also include, whenever the sample size permits, data disaggregated by educational enrollment, marital status, and sexual activity status, circumstances that can have serious implications for the health, social, and economic conditions of a young person's life.

Given the sampling methodology of the DHS, data are representative at the national, regional, and urban/rural levels for all age and sex cohorts, allowing for accurate estimations of target-population sizes for use in program planning and design. Table 1 shows data on social isolation for young people aged 10-14 who are not living with their parents and not enrolled in school, from the 2005 Rwanda

Table 1 Social isolation among 10-14-year-olds by sex, region, and urban/rural residence, Rwanda

Percent of 10-14 year olds not in school and not living with either parent

\begin{tabular}{lcc}
\hline Region & Girls & Boys \\
\hline Ville de Kigali & 12.2 & 4.6 \\
Kigali Ngali & 7.2 & 7.2 \\
Gitarama & 4.6 & 8.9 \\
Butare & 7.0 & 11.5 \\
Gikongoro & 7.2 & 8.4 \\
Cyangugu & 4.8 & 5.4 \\
Kibuye & 2.9 & 4.7 \\
Gisenyi & 5.7 & 7.4 \\
Ruhengeri & 3.6 & 3.3 \\
Byumba & 7.7 & 4.7 \\
Umutara & 4.6 & 5.6 \\
Kibungo & 3.0 & 6.4 \\
Urban & 8.6 & 6.7 \\
Rural & 5.1 & 6.6 \\
National & 5.6 & 6.6 \\
\hline
\end{tabular}

Source: Population Council 2009b. 
Figure 1 Percent enrolled in school among 10-17-year-olds, by age, sex, and urban/rural residence, Pakistan

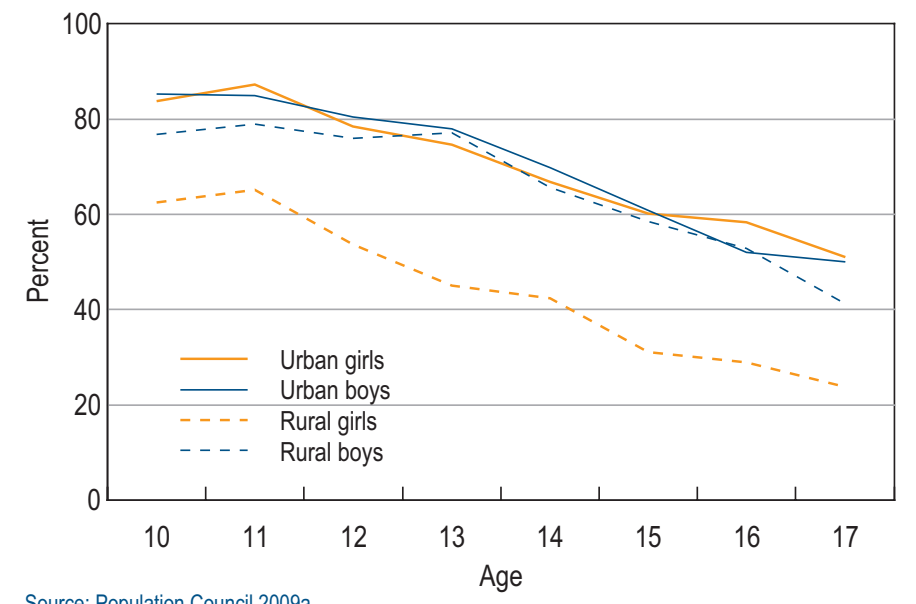

Source: Population Council 2009a

DHS Adolescent Data Guide. The data show that in some regions more than 10 percent of boys or girls are living in these conditions; rates for girls are higher in urban than rural areas. Tables such as these are common throughout the Data Guides and provide information about populations of interest for advocacy groups, decisionmakers, and other stakeholders.

In addition to tables, the Data Guides include charts and maps to offer a graphic representation of the same information. Figure 1 highlights the differences among rural and urban males and females with respect to school enrollment in Pakistan. Rural females are enrolled in school at much lower proportions than their urban counterparts and than males from both urban and rural areas. Additionally, a precipitous decrease is found in school enrollment among rural females that begins around the age of 11 . This finding suggests that program staff seeking to improve the educational attainment of rural girls in Pakistan should target girls before large proportions of them begin to leave school around the age of 11 and 12.

Maps are an easily interpretable representation of the geographic distribution of data that are accessible a wide range of people. They have proved to be a highly effective tool for conveying important messages about variations in indicators across subnational areas so that scarce programmatic resources can be concentrated where the need is the greatest. Figure 2 is a map of illiteracy among 15-19-year-old females in Zambia. Illiteracy among young women in Zambia is particularly acute in the North Western region as well as
Figure 2 Illiteracy among 15-19 year old females, Zambia

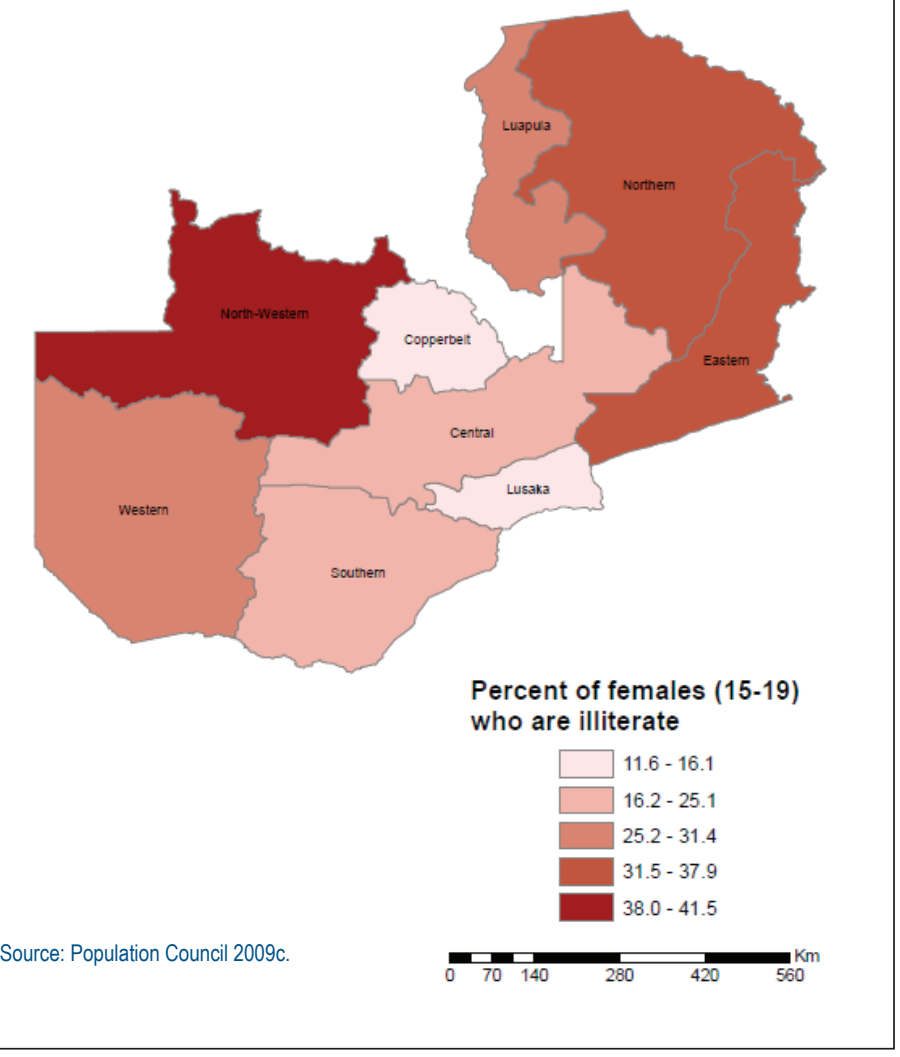

in the Northern and Eastern regions. Data displayed in this format speak volumes about the nature of the issue in a way that helps decisionmakers and planners easily comprehend how it plays out in their geographic area of interest.

\section{Available resources}

One of the primary goals of the Population Council is to conduct research that leads to programs and policies that help adolescents to emerge as healthy adults with skills that permit them to participate fully in work, family, and community life. By expanding the traditional lines of inquiry and recognizing the immense diversity that exists within the 10-24-year age group, Council researchers are shedding light on which adolescents are the most vulnerable and, therefore, most in need of targeted assistance. As new DHS reports are released, updated versions of the Data Guides will be produced. They can be found on the Population Council's website at: www.popcouncil.org/publications/serialsbriefs/ AdolExpInDepth.asp 


\section{References and resources}

MeasureDHS. 2011. "About DHS." www.measuredhs.com. Accessed 10 March 2011.

Population Council. 2009a. Adolescents In-Depth: Using Data to Identify and Reach the Most Vulnerable Young People-Pakistan 2006-07. New York: Population Council.

Population Council. 2009b. Adolescents In-Depth: Using Data to Identify and Reach the Most Vulnerable Young People-Rwanda 2005. New York: Population Council.
Population Council. 2009c. Adolescents In-Depth: Using Data to Identify and Reach the Most Vulnerable Young People-Zambia 2007. New York: Population Council.

\section{Donors}

Department for International Development (DFID)

United Nations Population Fund (UNFPA)

(P.pulation Council

The Population Council changes the way the world thinks about critical health and development issues. We seek to understand the causes and consequences of gender inequality and the disparities in opportunity that arise during adolescence. We provide the evidence for better on-theground programs and policies that ensure successful and productive transitions to adulthood in developing countries. www.popcouncil.org

(C) 2011 The Population Council, Inc. 